\title{
Editorial
}

\section{Las revistas académicas como plataforma para la construcción de conocimiento contable}

\author{
Hugo A. Macías Cardona \\ Profesor Asociado, Universidad de Medellín
}

Las revistas contables latinoamericanas tienen un bajo nivel de desarrollo comparadas internacionalmente, sobre todo por sus escasos aportes a la academia contable mundial. La baja contribución y el desconocimiento que se tiene internacionalmente de las revistas de todas las áreas producidas en nuestra región, se ha llamado hace más de una década la "ciencia perdida". En el número 12 de la Revista Lúmina se publicó un artículo sobre ese asunto (Macías \& Moncada, 2011), que ha causado reacciones diversas, entre ellas la expresada en el número 32 de Cuadernos de Contabilidad (Rueda, 2012) y las apreciaciones que estamos planteando en este número de Investigación y Reflexión, con los profesores, Fredy LeónPaime y Mauricio Gómez. En este aparte, se propone una reflexión sobre los avances y uno de los desafíos que enfrentan las revistas contables en Colombia.

La cualificación formal de las revistas contables colombianas ha sido un proceso tardío, en comparación con las revistas de economía y las de administración; se ha indexado un número bajo de revistas y solo una de ellas ha trascendido el nivel mínimo de indexación; sin embargo, estas revistas han avanzado más que revistas de campos cercanos como el mercadeo y los negocios internacionales (Macías \& Cortés, 2009). En el entorno latinoamericano, si bien las revistas contables colombianas son superadas de lejos por las revistas brasileras, como conjunto las colombianas están en una posición más cualificada que las revistas contables de Argentina, Chile, México y Venezuela (Macías \& Moncada, 2011).

En este aparte se pretende tomar una posición frente a la discusión actual sobre el sentido de las revistas contables en Colombia. La evidencia muestra que el ambiente institucional está llevando a que las revistas se adecúen cada vez más a los indicadores internacionales, bien sea desde el punto de vista de los editores, como lo han logrado los profesores Fredy León-Paime y Gabriel Rueda, o desde el punto de vista de los autores de revista ISI, como el profesor Mauricio Gómez. De manera paralela a los esfuerzos por avanzar en las indexaciones y el sentido de esos avances (Rueda, 2008; Rueda, 2011a; Rueda, 2011b; Rueda, 2012), es necesario tomar una posición que resalte la necesidad de hacer un esfuerzo de consolidación de la comunidad académica nacional, en el sentido de que los resultados sean conocidos colectivamente y permitan avanzar de manera colectiva. 
Necesitamos transitar desde la reflexión, como acto de volver sobre sí mismo, al pensamiento, como proceso colectivo; necesitamos superar el egoísmo y la búsqueda de beneficio individual, propios de la economía neoclásica, para redundar en beneficio colectivo (Gómez, 2011). Se trata de una "construcción cultural", como proceso amplio y complejo, que retome la tradición, las prácticas y la interacción de los actores (Suárez, 2009). No es posible trascender los monólogos auto-referenciales, ni se pueden hacer aportes, si se ignora lo que los colegas están trabajando en la misma línea; los artículos publicados en las revistas deben consultar y citar lo que los colegas hacen. ¿Si no construimos colectivamente, sobre qué construimos? La academia contable es por naturaleza social, no individual, necesitamos escapar de esta posición auto-referencial que un investigador brasilero llamó "narciso sin espejo" (Vieira, 2003).

Los planteamientos anteriores parecieran solo un discurso normativo, otro monólogo sobre el deber ser, pero son el resultado de una exploración preliminar sobre la estructura de las revistas contables colombianas y de los artículos publicados en ellas. Las revistas especializadas en el campo contable que han estado indexadas son: Cuadernos de Contabilidad, de la Pontificia Universidad Javeriana, que ha adquirido la categoría más alta entre las revistas contables; la Revista Lúmina, de la Universidad de Manizales, que fue la primera en indexarse y ha mantenido desde entonces la categoría C; y la revista Contaduría Universidad de Antioquia, que fue indexada en 2008, tiene también una larga tradición, pero no ha renovado su indexación. Formalmente, estas son las principales revistas contables colombianas y son las más conocidas entre los investigadores de las distintas ciudades.

La estructura de las revistas académicas tiene un amplio número de componentes. En este aparte del "debate polifónico" "se hará referencia solo al uso de referentes nacionales para la construcción colectiva de conocimiento contable en las revistas indexadas, y a características generales de revistas contables que no han estado indexadas. Para el caso de las primeras, el análisis de las referencias bibliográficos revela que la principal fuente citada por los autores de las tres revistas, son libros en español de autores extranjeros. En los números 25, 26, 27 y 28 de Cuadernos de Contabilidad, el 32\% del total de citas se refiere a libros internacionales y el $29 \%$ a documentos de Internet, dejando sólo un $10 \%$ a artículos nacionales y $2 \%$ a ponencias nacionales. En el número 10 de la Revista Lúmina, el $62 \%$ de las citas son de libros en español, $3 \%$ a artículos nacionales de las revistas contables y $4 \%$ a ponencias. Por su parte, el número 54 la Contaduría Universidad de Antioquia, usa libros como fuente en un $40 \%$, revistas contables indexadas en $1,6 \%$, la revista de Legis en el $3 \%$ y ponencias $0,4 \%$.

El punto aquí es que los libros son una fuente muy importante para los procesos de formación, porque representan el conocimiento acumulado, pero no deberían ser la fuente principal de un espacio cuya naturaleza es el intento de generar nuevo conocimiento y las discusiones deberían estar centradas en las fuentes que están en discusión, que son precisamente los artículos publicados en las diferentes revistas. Además, muchos de los

1 La expresión "debate polifónico" fue acuñada por un grupo de académicos europeos que se reunieron en 2005 para discutir el futuro de la investigación contable interpretativa; las memorias de su debate fueron publicadas en Critical Perspectives on Accounting en 2008, con un formato particular: un solo documento escrito por 15 autores, con secciones independientes y criterios de forma unificados. Varios documentos se han escrito después en respuesta a ese "debate polifónico". 
libros tienen problemas de actualidad, en el sentido que su versión original normalmente se editó en inglés, pasó alrededor de una década para su traducción, y desde esta última ha pasado cerca de otra década; estaríamos hablando entonces que las fuentes principales de las discusiones podrían estar desactualizadas en décadas. Las revistas contables de alto impacto en el mundo y las revistas brasileras que se han cualificado de manera visible en la última década, acuden a los artículos de revista como su fuente principal y citan sólo los libros clásicos o los libros producto de encuentros especializados. A los problemas que representa la formación y la investigación con base en libros de origen extranjero, han hecho referencia varios colegas, entre ellos la profesora Patricia González (González, 2010). En general, los artículos publicados en las 3 revistas contables indexadas acuden a las mismas revistas solo en el $2 \%$ de las fuentes, lo cual indica que no se está llevando a cabo un proceso colectivo de construcción de conocimiento; quiere decir que los autores no tienen en cuenta las discusiones que se están dando en las propias revistas, aunque sea para manifestar el desacuerdo.

Curiosamente, la revista que más citan los autores en las revistas contables indexadas es la "Revista Internacional Legis de Contabilidad \& Auditoría" (RILC\&A); es decir, esta última tiene mayor impacto académico que las revistas contables indexadas. Además, es la única que cuenta con un estudio bibliométrico completo y actualizado, que fue publicado en 2012 por el profesor Gerardo Santos. La revista tiene una considerable trayectoria, ha producido cerca de 300 artículos contables, se ha convertido en un punto de encuentro entre la academia y el sector profesional, se ha especializado en contabilidad financiera, auditoría y regulación internacional, al tiempo que se ha convertido en la revista contable colombiana con mayor nivel de internacionalización (Santos, 2012). Sin embargo, los autores que escriben en ella no construyen conocimiento de manera colectiva, en el sentido de considerar las discusiones que se han dado previamente en la misma revista y tener un alto nivel de coautorías con profesionales y entre académicos; así mismo, su naturaleza de revista basada en la academia, orientada al sector profesional, le ha impedido penetrar las bases de datos nacionales e internacionales, lo cual constituye una importante debilidad, ya que su presencia a texto completo en las bases de datos aumentaría visiblemente el nivel de circulación y de impacto académico.

Pero la publicación de artículos contables no se reduce a estas 4 revistas, que son las más visibles, sino que existe un grupo amplio de revistas especializadas que es necesario integrar a este proceso de construcción colectiva de conocimiento contable. Una de ellas es a Revista Activos, cuyos tres números más recientes dan cuenta de participación directa de connotados académicos internacionales, quienes aparecen de manera simultánea con profesores de tiempo completo y de cátedra, con profesionales y con estudiantes; se trata de una revista plural en autores, temas, posturas epistemológicas y abordajes metodológicos (Revista Activos, 2011); sin embargo, es una revista que ha tenido problemas de continuidad y no ha logrado aglutinar una comunidad académica que construya a través de ella; es decir construir conocimiento de manera colectiva.

Por su parte, la revista "Visión Contable" se ha estabilizado recientemente como una revista anual; temáticamente privilegia las líneas de tributación y formación del contador; da visibilidad a la producción académica de semilleros de investigación y ha logrado atraer como autores a profesores muy conocidos en la academia nacional y a estudiantes de maestría (Visión Contable, 2012). Algunas debilidades identificadas en ella se refieren a 
que la mayoría de los artículos publicados tienen pocas referencias bibliográficas y la mayoría de los autores tienen vínculos académicos con la universidad editora. Recientemente asumió la edición de la revista el profesor John Henry Cortés, quien ha acumulado una exitosa experiencia en el equipo editorial de la Revista Lúmina.

Así mismo, la Asociación Colombiana de Facultades de Contaduría Pública, creó la Revista ASFACOP, que se publicó cada dos años entre 1996 y 2005, en 2007 se empezó a publicar cada semestre, pero desde 2009 es una revista anual. La Asociación ha publicado 14 números de la revista en un periodo de 15 años, en 2012 cambió su denominación por "Revista Colombiana de Contabilidad" y está empezando formalmente su proceso de cualificación para ser indexada por Colciencias (ASFACOP, 2012). Un proyecto editorial más joven es la revista "Colombian Accounting Journal", de edición anual, con orientación principal hacia la contabilidad financiera; algunos artículos se publican en inglés y tiene alta participación de autores extranjeros; a esta revista le hace falta estabilizar su periodicidad, formalizar su presencia en las bases de datos latinoamericanas y aumentar la participación de la literatura nacional como fuente de la discusión colectiva.

Otra revista que ha construido una tradición con 15 ediciones, es la revista "Apuntes Contables", la cual inició publicando un número muy bajo de artículos y lo ha venido aumentando; ya está disponible en el sistema OJS (Apuntes Contables, 2012), pero un número alto de sus artículos publicados no está relacionado con la contabilidad y otros de ellos en ediciones anteriores no tienen las características corrientes de una publicación que tenga pretensiones de indexación. También existen algunos proyectos editoriales jóvenes, como el que está impulsando el profesor Adolfo Carbal en Cartagena y otros que no están especializados en contabilidad, pero que publican artículos contables, como el caso "Teuken Bidikay" y "Criterio Libre" (indexadas recientemente), "Porik-An", "Cuadernos de Administración" e "Innovar". En los últimos años se han dado debates contables en Investigación y Reflexión, revista que ha ganado un importante prestigio en la comunidad contable nacional.

La revista más leída y citada por los estudiantes es "Contaduría Universidad de Antioquia", en la publicación propia de los estudiantes de esa institución: la revista "Adversia". En "Adversia" escriben solo estudiantes de Contaduría Pública y la principal referencia de esos artículos son los artículos publicados en la revista de los profesores. Ellos están haciendo comunidad y lo hacen de manera escrita, con un enfoque particular de la revista, claramente de orientación crítica, alternativa, los autores no le hacen el juego a las revistas de corriente principal, acuden a la interdisciplinariedad con las ciencias sociales y en muchos casos hacen críticas radicales. Eso es academia, eso es comunidad, eso es identidad. Tenemos mucho que aprender también de los estudiantes interesados en investigación.

Una generación de artículos bien construidos contribuirá a que los que se escriban después tengan una estructura más ajustada a la construcción colectiva de conocimiento. Como lo plantea el profesor Walter Sánchez, rescatemos a los académicos con vocación de los que tienen un trabajo como profesor (Sánchez, 2011), y trabajemos con esos, dejemos atrás los monólogos. De los académicos con vocación hacen parte tanto aquellos que ostentan títulos de doctorado, como los que han realizado estudios de maestría, profesores apasionados por la investigación contable que no ostentan títulos y, tal vez en primer lugar, estudiantes de pregrado que están construyendo academia contable de alto nivel, a partir de semilleros de investigación desarrollados en diferentes ciudades. 
Para terminar esta sucinta participación, vale la pena reiterar la necesidad de construir conocimiento, como un proceso colectivo. El conocimiento contable colombiano solo podrá avanzar en la medida en que los resultados de investigación sean discutidos colectivamente, en que superemos los monólogos auto-referenciales y la posición de "narciso sin espejo". El mensaje que se pretende transmitir en este texto se puede expresar en una sola frase: en Colombia necesitamos desarrollar un escenario colectivo, interdependiente, de uso y generación de conocimiento contable, donde las revistas sean el capital simbólico central.

\title{
Revistas Académicas en Contabilidad: La búsqueda de sentido contextual
}

\author{
Mauricio Gómez Villegas \\ Profesor, Universidad Nacional de Colombia
}

Las revistas académicas han sido determinantes en el desarrollo, consolidación y validación del conocimiento científico y social. Estos medios de comunicación y difusión del conocimiento no sólo juegan un rol epistemológico, sino que también desempeñan un papel sociológico y "organizacional" muy importante. En la sociedad del conocimiento la dinámica de las revistas académicas se transforma. En las últimas décadas la academia contable en Colombia se encuentra en una etapa de crecimiento y los esfuerzos editoriales de este tipo vienen en aumento. Por tanto, resulta conveniente evaluar el papel de las revistas académicas, a partir de las experiencias internacionales y de las condiciones locales, con el fin de plantear estrategias para el desarrollo de éstas en el ambito contable en el país. Por consiguiente, resulta relevante preguntarnos: ¿Cuál debe ser el objetivo de las revistas académicas contables colombianas en el actual momento y de cara al mediano plazo?

Para abordar esta pregunta, primero se presenta algunos elementos constitutivos de los roles epistemológico y sociológico de las revistas en sus inicios. Luego sintetizamos algunas características contemporáneas de estas publicaciones, remarcando las posibilidades $y$ riesgos de algunas tendencias que se observan a nivel internacional. Finalizamos planteando posturas estratégicas para el desarrollo de las revistas académicas contables en Colombia.

\section{Roles de las revistas académicas en sus orígenes}

Las visiones convencionales otorgan a la ciencia la responsabilidad de construir conocimiento con capacidad de control y predicción sobre los objetos de estudio de la realidad. Esta pretensión humana se asocia a la visión positivista, propia de las ciencias naturales. La experimentación y la posibilidad de replica de tales experimentos, está en la base del conocimiento y re-conocimiento de la verdad que esta postura asume. Los primeros científicos, que fueron sobre todo filósofos e intelectuales, se convocaban en sociedad para re-crear públicamente sus experimentos y observaciones de los fenómenos que les preocupaban. Esto está en la base de las múltiples sociedades surgidas en el renacimiento y la ilustración Europea, tales como la Royal Society. Estos son los prolegómenos de las contemporáneas comunidades científicas (Merton, 1938). La experimentación y la validación del conocimiento en comunidad por parte de los pares, son desde entonces concebidas 
como el camino "epistemológico" del avance de la capacidad científica para descifrar, y codificar, el universo.

Con el nacimiento y desarrollo de las ciencias sociales desde finales del siglo XVIII, el debate sobre el sentido de la experimentación y la hegemonía del monismo metodológico ${ }^{2}$ se incrementa. Solo con el siglo XIX se plantea que las ciencias humanas y sociales discurren por otros caminos de construcción y validación del conocimiento, distintos al positivismo. Allí, la tradición de construcción de la ciencia retoma la comprensión y el raciocinio crítico, propios del racionalismo y el normativismo. Ello implicó una contrastación y una difusión del conocimiento soportadas en la producción de textos y obras escritas. De las lecturas de estas obras, surgían sendas epístolas privadas, y muchas veces públicas, como reacciones que avivaron el debate, los intercambios, los acuerdos y los grandes vacíos de la polémica incesante (Mardones, 1991).

Con la expansión legitimada de la educación universitaria y con la especialización del trabajo que ello reclama, surgen múltiples disciplinas de conocimiento y se estructuran los grupos de especialistas que les dan soporte. Es al interior de esta dinámica que se posicionan las revistas como medios de difusión, comunicación y replica del conocimiento disciplinario, en el sentido Foucultiano. Muchas revistas surgen fuera de la universidad, gracias a la tradición de las antiguas Societies ilustradas, pero también debido al auspicio de las profesiones liberales que promovió la universidad. Luego, con los cambios socioeconómicos y la formalización y profesionalización de la investigación al interior de las universidades, es que muchas de ellas inician la edición y producción de estas publicaciones seriadas.

De esta forma, las revistas han jugado un rol epistemológico determinante para satisfacer la necesidad de las comunidades científicas de intercambio, comunicación, difusión, contrastación y debate de sus hallazgos. Son manifestaciones de la voluntad de verdad (Foucault, 1999), que depende de la comunidad y de los cánones de responsabilidad y rigor que le acompañan. La comunidad científica válida lo verdadero.

También se desprende de ello, por consiguiente, un rol sociológico muy importante de las revistas. Ayudan a estructurar y controlar la dinámica al interior del grupo de científicos y de los mecanismos para hacer parte del mismo. Si para ser científico en el siglo XVI se necesitaba replicar el experimento frente a toda la Society, para ser científico en el siglo XX se necesita escribir en las revistas. Pero para publicar en las revistas, ahora no se es visto por "todos", sino que antes se es evaluado por "algunos", bien por pares "ciegos" (por paradójico que parezca), bien por el comité, o bien por el editor. Las revistas, por lo tanto, participan en la estructuración de la autoridad y la visibilidad de las comunidades científicas. Este es un rol sociológico y organizacional nada despreciable y que debe ser atendido, a la luz de los procesos contemporáneos de organización del trabajo de los "académicos".

\section{Las revistas científicas en la dinámica contemporánea}

Los cambios sociales experimentados con la revolución tecnológica son evidentes. En el contexto de una sociedad del conocimiento, hemos asistido a una significativa transforma-

2 Lo que implica unidad de método y homogeneidad doctrinal. 
ción en la dinámica de producción, apropiación, socialización y difusión del conocimiento. La Universidad va perdiendo lentamente la hegemonía en la investigación científica y la innovación técnica, tecnológica y organizacional se presentan de manera dispersa a partir de colaboraciones, redes e interacciones de verdadero alcance global.

La especificidad, el número, la periodicidad y la calidad de las revistas académicas se han multiplicado de forma geométrica, en el contexto de estas innovaciones y del proceso de producción del conocimiento. En este marco la universidad hace esfuerzos por adaptarse y competir con los conglomerados empresariales para mantener cierto dominio simbólico de los campos científicos, ampliando la edición de revistas propias. Con todo ello, el volumen de nuevas publicaciones ha promovido el surgimiento de índices que estiman la duplicación del acervo de lo escrito cada vez en menor tiempo.

Gracias a la internet se han abierto posibilidades de acceso, catalogación, clasificación y almacenamiento de las revistas académicas en sendas bases de datos en línea, administradas por empresas editoriales de envergadura multinacional. Múltiples Journals internacionales de origen universitario se han indizado en estas bases para promover su "visibilidad" internacional. Este proceso tiene muy positivas repercusiones para acceder a una cantidad enorme de información, que puede ser organizada con base en criterios flexibles de acuerdo a las necesidades y expectativas de los investigadores. Todo esto potencia la investigación académica, disminuyendo los costos sociales y privados del proceso y simplificando muchas de las etapas logísticas características de otros tiempos (desplazamientos a bibliotecas, lecturas de clasificación interminables, material inaccesible, construcción de bases de datos por cuenta propia, etc). Todo esto permite un acceso casi simultáneo a lo que se está produciendo en otras latitudes, limitando su abordaje a la capacidad de lectura (mayoritariamente en inglés), asimilación, comprensión, juicio crítico y contextualización por parte de los investigadores que disponen de los derechos de uso de las bases. Se promueven las redes de trabajo en un contexto internacional y se identifican con mayor claridad los temas y corrientes de opinión.

Estos beneficios contrastan con múltiples inconvenientes. Con el dinámico aumento de las publicaciones académicas, han surgido procesos de "evaluación de la calidad" de las revistas y los artículos, que son abordados desde un enfoque económico como "productos". Como casi todas las medidas de "calidad" basadas en el mercado, se han constituido rankings para clasificar a las revistas. Las de "mayor" calidad son las que aparecen en el Journal Citation Report. En esta lógica, la calidad se establece por la competencia para publicar en tales Journals. Esta competencia es motivada por la cantidad de citaciones que los artículos de las revistas reciben, medidas a través de índices de impacto desarrollados por las propias bases de datos que administran y comercializan los derechos de las revistas. Se establecen luego ubicaciones por cuartiles. En síntesis, se asume que ante un mayor volumen de académicos interesados en publicar en las revistas indizadas con mayor citación, los pares serán más "exigentes" con la dinámica de evaluación, lo que repercutirá en la calidad de lo publicado. Se parte del supuesto según el cual las revistas de mayor impacto publican los mayores avances científicos. En el fondo, a lo sumo, lo que se hace es regular un mercado de oferta de artículos para ser publicados.

Asumir que necesariamente mayor citación es mayor calidad y que ello es siempre mayor avance científico, es como confundir el "maquillaje con la belleza". Es cierto que se pu- 
blica para difundir y aportar, pero ser citados no es el único indicador de ello. Establecer el criterio de citación como medida del aporte, conduce a una lógica autorreferencial y creciente en el que hay que citar lo más citado para conseguir publicar. Como en todo proceso guiado por el mercado, hay una destrucción creativa que implica citar lo más reciente, haciendo obsoleto, en el marco de las expectativas y percepciones colectivas, lo más antiguo. Ubicarse en la "frontera" es conocer y citar las últimas publicaciones. En síntesis la cantidad, la novedad como lo reciente, el éxito científico como la primicia, confluyen y se tornan la lógica que se sobrepone a la "voluntad de verdad" propia del ethos originario de las comunidades científicas. Hoy se posiciona para los académicos a nivel internacional la expresión "publicar o perecer" que quiere connotar que la estructura organizacional de las carreras académicas se ve atravesada por estos procesos.

De todo ello, pueden plantearse diversas conclusiones, con múltiples matices de análisis. Algunas de las consecuencias más críticas tienen que ver con: i) la hegemonía epistemológica y metodológica que las revistas líderes o de mayor "calidad" impone (Hopwood, 2007); ii) el conjunto de incentivos que la dinámica de publicaciones irradia para administrar las carreras académicas de los investigadores-docentes (Demski, 2007); iii) la paulatina pérdida de utilidad y relevancia contextual de la investigación básica y aplicada por la presión de la publicación en revistas líderes internacionales; y iv) la tendencia mercantil, privatizadora y oligopólica de la administración de las revistas que se impone, en especial, a través de las bases de datos.

\section{Aprendizaje prospectivo para las revistas contables en nuestro contexto}

El desarrollo académico de la disciplina contable en el país viene mejorando tanto cuantitativa, como cualitativamente. La profesionalización de la academia contable está incrementándose, bien por regulaciones, bien por isomorfismo con otras disciplinas, bien por tendencias institucionales. Es conveniente, ante la dimensión e implicaciones de la profesión, que la academia contable se fortalezca, para aportar de manera decidida al desarrollo profesional, al avance social y al interés público. Varios elementos permiten diagnosticar este avance. El volumen y variedad de eventos académicos viene creciendo. El número de profesores de tiempo completo en facultades y programas se incrementa, al igual que su cualificación académica. Crecen los grupos de investigación formalmente reconocidos. Se institucionalizan campos disciplinares, tales como la teoría contable y la investigación contable. Surgen programas de maestría concretamente en la disciplina, entre algunos otros indicadores.

A propósito del tema que nos ocupa han surgido, y se han mantenido, proyectos editoriales de revistas específicamente contables, y otras con alcance a las ciencias económicas, que divulgan los avances de la disciplina surgidos en el país. Apropósito de la dinámica de estas publicaciones y de su derrotero futuro, se han suscitado debates, posturas diversas y cuidadosos análisis (León, 2009; Macías \& Moncada, 2011; Rueda, 2012).

Algunos profesores-investigadores argumentan que el camino a seguir por nuestras publicaciones es el de iniciar el proceso de indización con los criterios internacionales. O por lo menos adoptar el ideario de la citación, como medida de la visibilidad y la consolidación de "escuela" o "comunidad académica" en el país. Pensamos, por lo previamente argumentado, que en este momento ese proceso implica riesgos que pueden promover 
incentivos nocivos que no ayudarían a fortalecer suficientemente la consolidación de la contabilidad académica en nuestro contexto.

El tránsito a la dinámica internacional puede resultar prematuro, porque aun debemos decantar los procesos cualitativamente en el país. Con los riesgos que las tendencias muestran, este tránsito prematuro es aún más complejo. La dinámica de formación en posgrados propiamente contables está iniciando, con lo que las tradiciones metodológicas específicas del campo y de los problemas contables están por difundirse, discutirse y contrastarse. Es cierto que hay un legado de reflexión, pero se ésta aún en mora de sistematizar mejor este legado. Los ejemplares teóricos aún deben abordarse, conocerse, de-construirse y contrastarse de manera metódica. Se requiere mayor investigación empírica, bajo los más diversos enfoques y tradiciones metodológicas, para poder aportar al entorno nacional e internacional nuestros hallazgos. En síntesis, se requiere decantación, modernidad antes que simple modernización (Corredor, 1992).

Se plantea que el papel de nuestras publicaciones actualmente y en el mediano plazo es apoyar a esta decantación. Promover la lectura en procesos pedagógicos y propedéuticos de nuestros estudiantes. Impulsar la investigación formativa, disponiendo debates y reflexiones sobre las contextualizaciones de tradiciones teóricas y metodológicas internacionales. Y sobre todo, ser fuente de difusión y ensayo de la publicación de las investigaciones contextuales de los profesores y de los profesionales en formación a nivel de maestría. Claro, a la vez pueden servir de vínculo para contrastar lo investigado en otras latitudes.

Transitar a la dinámica de indización internacional ahora, cumpliendo con los criterios actuales, puede generar unos incentivos que catapulten a un reducido grupo de investigadores, so pena de limitar el avance en la investigación contextual, la dinámica propedéutica de la investigación formativa y la verdadera "común unión" de objetivos.

Otra forma de categorización de la calidad de las publicaciones no es tan sólo posible, es indispensable. Y esto puede ayudar a diseñar unos mejores incentivos para la construcción de comunidad académica contable en nuestro contexto.

\section{La comunidad contable y sus publicaciones: Consideraciones modernas sobre su ser}

\section{Edison Fredy León Paime Profesor, Universidad Militar Nueva Granada}

Reflexionar sobre el estado de las revistas científicas en contabilidad en Colombia es aventurarse a criticar la fachada de una casa en construcción. Las publicaciones son la fachada de una casa denominada comunidad escolar/científica. Una casa en construcción, con algunos cimientos endebles y otros muy fuertes. Juzgar una estructura por su fachada es obviar sus partes, sus relaciones con otros objetos (internos y externos). En el marco de la construcción colectiva de esta reflexión, me permito plantear que podemos establecer un dialogo, no sobre el estado, sino más bien sobre el proceso, ¿por qué la fachada aún no cubre la casa? 
Las publicaciones científicas en contabilidad vienen siendo un tema recurrente de análisis en diferentes contextos. En el contexto internacional, es común hablar de los top y ranking de las publicaciones, los cuales generan múltiples clasificaciones (ilusiones de la verdadera ciencia). Poderosos miembros y corporaciones como Thompson-Reuters, Elsevier, Emerald, entre otros, disputan el mercado de la publicación científica, tendiendo redes de colaboración e imposición de modelos de gestión editorial. Hacer parte, indexarse, generar la visibilidad que cuenta, es una pesadilla para editores y autores, una oportunidad para consultores y un lugar donde presionar para los gestores educativos.

Por otro lado, como fruto de los procesos de revisión de literatura, los académicos terminan examinándose así mismos. Esto genera una relación, donde se analiza al pariente, al vecino, al competidor, al legítimo y al que consideran ilegitimo. Son numerosos los trabajos que hacen eco a los rankings, detallan los autores más citados, y emplean la rigurosa métrica del impacto del trabajo. Hacer visible el trabajo, generar puentes de interpretación es una opción valida y necesaria en el proceso de reconocimiento de un campo de saber, pero es a la par, un ejercicio de fortalecimientos de los egos y de expansión del status quo.

En Colombia no estamos lejos de estas discusiones, entrañables colegas han realizado comprensivas reflexiones tratando de entender el porque la fachada no esta completa, y cómo, de una manera u otra, se siente frustración por ello. Frustración hija del conflicto entre deseos, justificaciones y exigencias institucionales. Como autores y editores, estamos aprendiendo a navegar en estas reglas de juego, cimentando ladrillos que no encajan e instalando ventanas sin vidrios. Este editorial colectivo nace en el marco de esa conmoción.

La forma de nuestra casa y su fachada dependen de dos aspectos, el primero, el lugar que ocupan las publicaciones en la tradición del gremio profesional de los/las contables colombianos(as), y en segundo lugar, las aspiraciones de las instituciones educativas frente a las demandas del sistema de ciencia y tecnología C\&T. Los argumentos que, en mi opinión considero deben ser tenidos en cuenta y que se vinculan con las revistas y publicaciones científicas en contabilidad serán presentados a continuación.

\section{Legitimidad de las publicaciones frente al gremio que conocemos y el que no}

El gremio contable en Colombia es una red de relaciones sociales, la cual reconocemos de manera muy parcial. Caracterizarlo, aunque es un proceso necesario, no es suficiente. Generalmente nos preocupamos por algunos agentes del gremio como lo son los docentes/investigadores, los estudiantes; prestamos una menor atención hacia los y las profesionales, pero ignoramos buena parte de otros agentes que también hacen parte de ese campo (directivos, practicantes empíricos, especialistas temporales, etc.), lo cual no nos permite reconocer los límites del cuerpo de práctica. Somos en esencia un grupo diverso, con múltiples intereses y posibilidades de experiencia de vida.

La forma como tradicionalmente hemos reconocido el campo contable, es también la forma como lo hemos moldeado. Hemos historizado tradicionalmente la disciplina en función de dos ámbitos, las acciones de sus autoridades y la agenda profesionalista. Por un lado, la escritura de la contabilidad colombiana a partir de las autoridades, no ha logrado involucrar el sentido que los y las practicantes dan en la cotidianidad a su experiencia, crea discursos comprensivos parciales, no por ello carentes de sentido. Por otro lado, la agenda profesio- 
nalista ha centrado su quehacer en los ámbitos de la respuesta ante el cambio técnico y la protección del capital simbólico gremial, en función de la dinámica del mercado profesional.

No es que los docentes/investigadores no reconozcan su/la realidad, sino que, ante la imposición de la agenda profesionalista y la ausencia de instrumentos para la comprensión del otro, no se crearon las condiciones para generar una dinámica de interacción discursiva, un proceso de comunicación, incluso con los pares. La escritura de nuestras experiencias, en últimas, es uno de las actividades que mas nos constituye en sujetos modernos.

La interacción discursiva de pares del gremio requiere del reconocimiento pleno del otro como sujeto racional y argumental, como ámbito esencial para que la comunicación académico/gremial fluya. La interacción discursiva es necesaria, para considerar válido lo del colega, incluso lo del contrincante ideológico, esto es conceder la necesidad de dialogo. Hacer del otro un integrante de dialogo es crear la disposición básica de una comunidad comunicativa. Mas es este el primer problema que quería señalar, pues conocemos la comunidad del gremio profesional contable del país, pero aun desconocemos su dimensión comunicativa. Como resultado, tenemos publicaciones que permiten la exposición de enunciados significativos de parte de sus miembros, pero no concretamos el dialogo critico/constructivo que permita identificar una flujo discursivo estable que aglutine a la comunidad. En este contexto, las publicaciones pueden estar careciendo la legitimidad suficiente de parte de la comunidad como puentes de comunicación. Si las publicaciones no son el escenario legitimo para que una comunidad discuta lo que se quiere ser, entonces ¿̇cual es?

\section{La presión externas: las instituciones universitarias y los sistemas de CET}

Si bien los gremios profesionales y su dinámica socio/comunicativa tienen un papel relevante como presión externa de la consolidación de las publicaciones científicas, la relación que estos tienen con las estructuras que permiten su reconocimiento como ámbitos de formación de nuevas generaciones y de estatuto pragmático del saber es compleja y fundamental. Sin embargo, este aspecto, no es fácil, ni para las instituciones universitarias, ni para las comunidades profesionales que concurren a esta. Los cambios recientes generan distorsiones y demandas que son difíciles de afrontar.

Las instituciones universitarias en Colombia pasan por un proceso social crítico, en el que de ser instituciones diseñadas (casi que originalmente), para la docencia, han tenido que construir en la última década las dinámicas necesarias para empezar a exponerse como casas de la investigación y la innovación. Estas últimas demandas no siempre estuvieron claras. Considero que las publicaciones han estado en función de la trasformación de la educación superior en Colombia.

La universidad colombiana ha tenido que vivir dos tipos de expansiones, una modernizante que integro las aspiraciones del desarrollismo criollo y que implico la ampliación limitada de cupos y coberturas asociadas a las necesidades de una élite, y la segunda una expansión competitiva que lleva a la confrontación de las capacidades instaladas frente a la dinámica de la producción y competencia internacional. Así, solo a finales del siglo XX en los últimos resquicios del dinámica expansiva modernizadora se empieza el proceso de conformación del sistema de C\&T, de tal manera que las instituciones universitarias debieron conformar políticas, grupos de investigación y publicaciones científicas que legitimaran su accionar. 
Este proceso ha sido arduo, incluso algunas instituciones aun no lograron articular la lógica de este tipo de política en su quehacer. Sin embargo, en la última década, sin que el anterior proceso se hubiera decantado, el sistema ha demandado a las universidades y su comunidades que entren rápidamente en la dinámica de medición y comparabilidad internacional, lo que significa, por una lado, el colocar los documentos de sus miembros en la revistas de mayor impacto según los estándares, y por el otro, transfigurar a sus publicaciones a que sigan tales reglas de juego. Tales desafíos se vienen afrontando, sin haber concretado las exigencias de la primera expansión, de tal modo que tales exigencias se constituyen en una presión frente a la cual la institución no se encontraba preparada.

Las comunidades asociadas a las publicaciones, que seguían unos sentires de identidad profesional, mas que de especialización académica, han tenido que afrontar ello, pero con un respaldo institucional limitado. Es importante plantear que subyace la creencia que concretando las demandas de la primera expansión, se puede llegar a la segunda con mejores condiciones. Sin embargo algunas comunidades, entre ellas la contable, aun tienen problemas para terminar de concretar la primera, situación que nos deja, bajo esta creencia, más lejos de afrontar la segunda. Comprender las reglas de juego de ambas lógicas de expansión, es algo que el cuerpo de la comunidad no ha interiorizado. Así mismo, sus integrantes (autores, editores, académicos) aun se encuentran descifrando el camino a seguir, cuando la presión por la legitimación de la productividad vía indicadores los viene arrastrando. De esta manera, la dinámica de la institución escolar y de las exigencias del sistema de C\&T no se constituye en un factor para la visibilizacion, sino para la per-formación de las comunidades (en especial de las nuevas generaciones). No se visibiliza lo que las comunidades son, se impone lo que deben ser, siendo ésta la sin salida del proceso.

\section{Déjanos escribir y ser}

En los años ochenta el mítico músico David Bowie abogo por la necesidad de dejar que las comunidades sean y vivan los procesos como quieran en su canción "Let's Dan$c e "$. El mensaje de mi intervención en este dialogo es el mismo, ante las presiones de la comunidad, la institución universitaria y el sistema de C\&T, autores(as), editores(as) investigadores(as) y demás agentes del campo tienen que tratar de "ser", queriendo "ser" y no solo respondiendo ante de las imágenes del "deber ser". En mi posición, creo que no se puede escapar a estas lógicas impuestas, pero no por ello quiere decir que debemos responder acríticamente a ellas. Nuestras características de comunidad nos seguirán generando barreras que nos impedirán jugar con eficiencia en el juego de la lógica productiva internacional, pero de eso se trata la construcción de comunidad.

La propuesta de este documento apela al fortalecimiento interno, ya que de nada sirve integrarnos a los índices, si estos no son indicadores de interacción discursiva. La citación y co-citacion son estrategias que pueden perder sentido, si con ello no hacemos un dialogo constructivo. El cumplimiento de parte de las publicaciones (no solo las contables), de estándares que permitan estar en índices de gran reconocimiento no tendrá ningún impacto si el consumo de tales creaciones culturales sigue limitando, en el más optimista de los escenarios, a unos pocos académicos. El intercambio significativo que logra confrontan las presiones internas y externas es un proceso que aun requiere sacrificio, reclama una nueva actitud de autores(as) y un compromiso, también performativo, de parte de editores(as). Ser una comunidad moderna, implica ser consientes que la decisión es nuestra. 
Es probable, que el impacto de nuestras comunidades, dadas las reglas de juego sea marginal. Pero se puede ser marginal con dignidad. No se trata de no escribir en las revistas de alto impacto, ni de no escribir en otros idiomas, o de no tratar que nuestras publicaciones suban sus estándares reconocidos, tales posiciones son inútiles y retardatarias, se trata de encontrar las temáticas discursivas que nos unan. Aquellas que nos permitan aglutinarnos y construir comunidad, no solo responder a las presiones de los sistemas C\&T y de las necesidades de legitimación universitaria. Quizás la velocidad sea mas lenta, pero el resultado se sentirá propio, ya que no se puede aplastar el proceso con la competencia internacional, cuando la semilla de la modernización comunicativa grupal aun no ha germinado. El camino esta lleno de esfuerzos, que vale la pena seguir para el bien de todos(as). Solo nos queda plantarnos ante el sistema y expresar, dejadnos seguir y construir una historicidad propia, abierta y cada vez más técnica en la escritura. Escribir para ser y no ser para escribir.

\section{Referencias}

Apuntes Contables (2012). Universidad Externado de Colombia. Recuperado el 19 de octubre de 2012, de Facultad de Contaduría Pública: http://revistas.uexternado.edu.co/index.php/ contad/index

ASFACOP (2012). Asociación Colombiana de Facultades de Contaduría Pública. Recuperado el 26 de octubre de 2012, de Revista Colombiana de Contabilidad: http://www.asfacop. org.co/joomla/index.php?option $=$ com_content\&view $=$ article \&id=53:publicaciones\&catid $=34$.

Corredor, C. (1992). Los límites de la Modernización. Cinep- Facultad de Ciencias Económicas. Universidad Nacional de Colombia.

Demski, J. (2007). Is Accounting an Academic Discipline? En: Accounting Horizons, 21 (2): 153-157.

Foucault, M. (1999). El Orden del Discurso. Editorial Tusquets. Barcelona.

Gómez, M. (2011). Pensando los fundamentos de la contabilidad como disciplina académica. En: Revista Lúmina 12: 120-150.

González, J. (2010). Desprofesionalización de la enseñanza y desarrollo del saber contable. En: Revista Activos 14: 1-6.

González, P. (2010). Avances y desafíos sobre la enseñanza de la contabilidad de gestión en Colombia: desde una perspectiva de mipymes y de la educación superior. En: Revista Universo Contábil, 6(3): 140-155.

Hopwood, A. (2007). Whither accounting research? En: The Accounting Review, 82 (5): 1365-1374

León, E. (2009). La educación contable en el contexto anglosajón: una mirada a los años de construcción de comunidad. En: Cuadernos de Contabilidad, 10(27): 219-245.

León, E. (2009). Delineando complejos cognitivos: la producción científica de las disciplinas económicas en América Latina. Contaduría Universidad de Antioquia, 54: 79-115.

Macías, H., \& Cortés, J. (2009). El campo de la investigación contable: oportunidades para los investigadores colombianos. Cuadernos de Contabilidad, 10(26): 21-50.
Macías, H., \& Moncada, T. (2011). El campo científico de la contabilidad. Panorama internacional de las revistas. En: Revista Lúmina, 12: 260-278.

Mardones, J. (1991). Filosofía de las Ciencias Humanas y Sociales. Editorial Arthropos.

Merton, R. (1938) Science, Technology and Society in SeventeenthCentury England. Osiris 4: 360-632.

Revista Activos (2011). Universidad Santo Tomás de Aquino. Recuperado el 19 de octubre de 2012, de Facultad de Contaduría Pública: http://contaduria.usta.edu.co/index.php/nuestrafacultad/2011-09-06-21-25-54/resvista-activos

Rueda, G. (2008). Editorial, pertinencia disciplinaria y profesional de la indexación. En: Cuadernos de Contabilidad, 9(25): 377-379.

Rueda, G. (2011a). A propósito de la reclasificación de Cuadernos de Contabilidad. El sentido de la indexación. Cuadernos de Contabilidad, 12(30): 9-13.

Rueda, G. (2011b). Editorial: El papel de las publicaciones científicas para la docencia. En: Cuadernos de Contabilidad, 12(31): 427-430.

Rueda, G. (2012). El sentido de buscar que Cuadernos de Contabilidad sea en el futuro una revista incluida en ISI. Cuadernos de Contabilidad, 13 (32): 10-14.

Sánchez, W. A. (2011). La docencia en el lugar equivocado. En: Revista Lúmina, (12): 240-259.

Santos, G. (2012). Aproximaciones a un análisis bibliométrico de la Revista Internacional Legis de Contabilidad \& Auditoría 2000-2012. En: Revista Internacional Legis de Contabilidad \& Auditoría, 15(49): 183-226.

Suárez, J. (2009). Lineamientos para la construcción del campocontable: un enfoque social-histórico. En: Revista Lúmina, (10): 8-32.

Vieira, F. (2003). Narciso sem espelho: a publicação brasileira de marketing. En: Revista de Administração de Empresas, 43(1), 91-90.

Visión Contable (2012). Universidad Autónoma Latinoamericana. Recuperado el 19 de octubre de 2012, de Programa de Contaduría Pública: http://www.unaula.edu.co/programas/pregrado/ contaduria/visioncont. 